\title{
Groundwater Quality Assessment of a Coastal Aquifer in Niger Delta Using Geo-electrical Techniques
}

\author{
Iheanyichukwu P.C. Okorie ${ }^{1}$, Adekunle O. Sofolabo ${ }^{2}$ \\ ${ }^{1,2}$ (Department of Physics (AppliedGeophysics)/ University of Port-Harcourt, Nigeria)
}

\begin{abstract}
The geo-electrical techniques involving the VES and 2-D resistivity imaging was used in assessing the groundwater quality of a coastal aquifer in Ogu-Bolo Local Government Area of Rivers State. This study used two Vertical Electrical Sounding data and three horizontal profiling data obtained using ABEM SAS 300B Terrameter. A computer modeling was used in processing the Data and partial curve matching was employed in the interpretation of the VES data. Five geoelectric layers of varying thicknesses, depth and resistivities were delineated. The fourth layer is where the best aquifer ranged from $41.70 \mathrm{~m}$ to $42.90 \mathrm{~m}$ at the various VES stations. The mean aquifer thickness, depth and resistivity value were calculated to be $23.74 \mathrm{~m}, 42.30 \mathrm{~m}$ and resistivity value of $3033.50 \Omega \mathrm{m}$. The results of the interpretation of the two VES stations and the 2-D data have offered the opportunity of knowing the possible aquiferious zone within the study area. The results reveal that beyond the depth of $15.00 \mathrm{~m}$ an aquifer system devoid of salt water intrusion will be possible.
\end{abstract}

Keywords: About five key words in alphabetical order, separated by comma (10 Italic)

\section{Introduction}

Safe water is a basic necessity of life and when it is not available and/or contaminated, it could have serious public health implications, ranging from diseases to outbreak of epidemics. In the past, rain water, streams, and lakes were the major sources of water to humans. However, they are unsuitable sources of drinkable water due to pollution and contamination as result of human activities [1].

The main source of potable water supply for domestic, industrial and agricultural uses in the southern part of Nigeria especially the Niger Delta, due to long retention time and natural filtration capacity of aquifers has been notably identified as groundwater [2]; [3]; [4].

The deterioration of water quality in the coastal areas due to salt water intrusion into the freshwater aquifer has become a major concern. Many communities in the Niger Delta are facing an acute shortage of portable water because of the surrounding expanse of seawater and tidal creeks. The increase in population in these areas and the resulting increase in groundwater consumption has added to the problem as seawater intrudes further inland in response to pumping. Other external influences such as tides and recharge events cause changes in the interface. Mapping of the fresh water/salt water interface(s) in most of the coastal aquifers is necessary in order to possibly provide many of these communities with adequate fresh potable water.

The Ogu Community in Ogu-Bolo Local Government Area consists of two settlements, namely: the Ogu Old layouts and the Ogu New layouts. An investigation in these communities reveals that the old layouts which are densely populated have boreholes that are devoid of salt water issues. The new layouts which were reclaimed and are sparsely occupied could possibly be associated with the prominent salt water problems which are associated with coastal communities in the Niger Delta Nigeria.

It is with this view in mind that this study intends to undertake the assessment of the groundwater quality of this community in the local government area.

\section{Location And Geology Of The Study Area}

The study was carried out in Ogu Community in Ogu-Bolo Local Government Area of Rivers State. It is located on Lat $4^{\circ} 40^{\prime} 10^{\prime \prime}$ North and Long $7^{\circ} 12^{\prime} 10^{\prime \prime}$ East. It is accessible through network of roads via Eleme, Okrika, and some other bounding communities (fig. 1.0).

The underlying sediments within this study area forms part of the stratigraphic sequence in the Niger Delta. They consist of unconsolidated fresh water bearing continental sands and gravels with occasional interbedded shale of the Benin Formation, deposited during the late Tertiary to early Quaternary period with an average thickness of about $2100 \mathrm{~m}$. The Benin Formation constitutes the main aquifer system of the study area and forms the main source of portable ground water supply. Structurally, the sediments in the area are deposited in the NW-SE trend and groundwater flow occurs in line with this trend [5]. However, local variations occur in places due to the anisotropic behaviour of the sediments. Rainfall in the area varies over a wide range in temporal context because of the occurrence of wet and dry season. 
The bulk of groundwater in the Niger Delta is contained in very thick and extensive sediments of Benin Formation. The exploited aquifers including Ogu-Bolo are derived from the Benin Formation. Figure 2.1 below shows the geologic map of the study area.

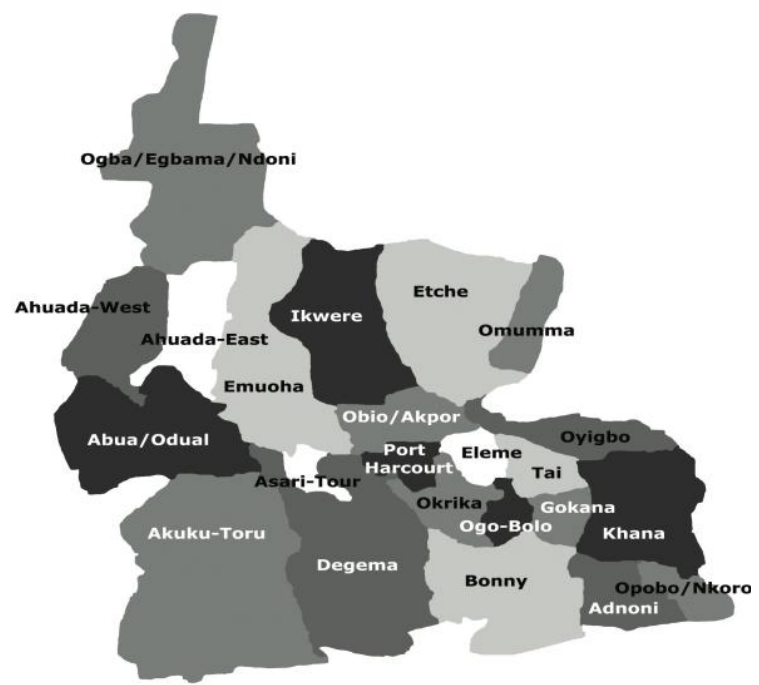

Fig 1. Map of Rivers State showing Ogu/Bolo Local Government Area

\section{Methodology}

Geo-electrical resistivity surveys are now commonly used for geotechnical investigations and environmental surveys [6]. The resistivity method is based on measurements using two electrodes, of the potential distribution arising when electric current is transmitted into geological layers through two other electrodes. The resistivity of the subsurface is affected by porosity, amount of water in the subsurface, ionic concentration of the pore fluid and composition of the subsurface material [7].

An assessment of the groundwater quality and groundwater aquifer system using vertical electrical sounding (VES) and 2-D resistivity imaging methods were used in this study. Two-dimensional resistivity surveys were carried out with a digital read out ABEM Teremeter SAS (Signal Averaging System) 300B, using the Wenner $-\alpha$ linear array configuration. Three profiles were acquired within this locality. Measurements were made at sequences of increasing offset distance (a-spacing) along the profile lines ranging from $5 \mathrm{~m}$ to $30 \mathrm{~m}$ for the $100 \mathrm{~m}$ spread and from $10 \mathrm{~m}$ to $60 \mathrm{~m}$ for the $200 \mathrm{~m}$ spread respectively using twenty (20) electrodes. The electrodes were moved from one end of the line to the other in a lip frog manner to achieve continuous horizontal resolution of the subsurface.

Two vertical electrical sounding (VES 1and 2) were also carried out using the same ABEM meter. VES 1 was acquired alongside Profile 1; while VES 2 was acquired alongside Profile 2. A maximum AB/2 distance of $150 \mathrm{~m}$ and $\mathrm{MN} / 2$ distance of $15 \mathrm{~m}$ were occupied. Finally, a record of the variation of the apparent resistivity of the subsurface with depth for each survey was obtained. This investigation was carried out during the dry season by which time the water table was at its deepest level.

\subsection{Data processing and presentation of results}

2D - Resistivity Imaging: The measured 2D resistivity imaging data were processed using the RES2DINV inversion software [6]. This program automatically subdivide the subsurface into a number of blocks and then uses a least -squares inversion scheme to determine the appropriate resistivity values for each blocks so that the calculated apparent resistivity values agrees with the measured apparent resistivity values from the field survey. The results are displayed as inverted model resistivity sections versus depth of the subsurface along the four profiles (Figures 2 to 4 ). The pseudo sections, consistently show similar structures with variation on the detail level with depth and were visually inspected to delineate areas of anomalously high or low resistivity relating to subsurface structures.

\subsubsection{PROFILE 1}

The profile was acquired along the same stretch with the vertical electrical sounding (VES 1). It covers a spread of about $100 \mathrm{~m}$ and a depth of about $15.6 \mathrm{~m}$. From the profile, an anomalously low resistivity zone $(<$ $12.3 \Omega \mathrm{m}$ ) was isolated at a shallow depth between $3.32 \mathrm{~m}$ and $9.30 \mathrm{~m}$. This is very high conductive body, which probably could be interpreted as salt water. There also exist an anomalously high resistivity zone $(<2173 \Omega \mathrm{m})$ lying adjacent to the conductive salt water and covering a spread of about $40 \mathrm{~m}$ and a depth of $7.27 \mathrm{~m}$ and beyond 
15.6m. These zones are interpreted as housing sands of varying sizes, and thicknesses with moisture. Good aquifer structures exist at depth greater than $15.6 \mathrm{~m}$. This region could be interpreted as housing the freshwater zone. The two anomalously low and high resistivity zones are separated by an impermeable layer of reasonable thickness having a resistivity value of $<2173 \Omega \mathrm{m}$ serving as an interface between the salt water and the fresh water.

\subsubsection{PROFILE 2}

The profile in figure 3 covers a distance of about $100 \mathrm{~m}$ and a depth of about $15.6 \mathrm{~m}$. Two major zones of different resistivity could be mapped. Isolated zones of anomalously low resistivity measuring $<115 \Omega \mathrm{m}$ and occurring at a shallow depth from the surface to about $11.4 \mathrm{~m}$ is assumed to contain conductive fluids believed to be saline water. This zones of anomalously low resistivity from is observed to be progressive. The region of anomalously high resistivity values measuring $>3492 \Omega \mathrm{m}$ and occurring at a shallow depth of $3.32 \mathrm{~m}$ and beyond $15.6 \mathrm{~m}$. This indicates the fresh water zone housing medium to coarse sand. The zone with yellow to red colour having an intermediate resistivity values could be identified as an impermeable layer made of clay.

\subsubsection{PROFILE 3}

Profile 3 is covering a long stretch of $200 \mathrm{~m}$ and while probing a vertical depth of $31.3 \mathrm{~m}$. The isolated zones of low resistivity in figures 2 and 3 are observed in figure 4 as a continuous body having a resistivity of $<1064 \Omega \mathrm{m}$. It is also occurring at a shallow depth from the surface to about $18.6 \mathrm{~m}$. This zone from all indication is assumed to be housing conductive fluids which could possibly be inferred to as saline water. The zone of anomalously high resistivity measuring $>23096 \Omega \mathrm{m}$ is observed to have been enveloped by the continuous conductive body thereby having a cone shape. This zone is believed to contain medium to coarse sand with the presence of freshwater which could be the cause of the high resistivity values. This freshwater zone is occurring at a shallow depth of $18.6 \mathrm{~m}$ and beyoud $31.3 \mathrm{~m}$.

Vertical Electrical Sounding (VES) Data: The Vertical Electrical Sounding field data was processed using the Schlumberger automatic analysis software [8]. This computer program automatically generates model curves using initial layer parameters (resistivities and thickness) derived from partial curve matching of the field curves with standard curves, and calculates the true layer parameters of the geo-electric section. The results are presented in terms of the resistivities, thicknesses and depths of the geo-electric section for the two VES positions (Table 1).

The resulting resistivity curves which shows plots of apparent resistivity (in ohm-m) against electrode spacing (in $\mathrm{m}$ ) for the three VES stations are shown in figures 3.1 and 3.2 respectively.

In figures 3.1 and 3.2 below, it is shown clearly that the apparent resistivities of the different geoelectric layers $\left(\rho_{1}<\rho_{2}<p_{a}<\rho_{4}>\rho_{5}\right)$ as obtained depicts that the curve types for the respective curves is "AK" and each of them show the presence of five (5) geoelectric sections. This is a good curve type for the existence of a viable groundwater aquifer.

The summarized results of the interpretation of the field report are presented in table 3.3 and 3.4 respectively.

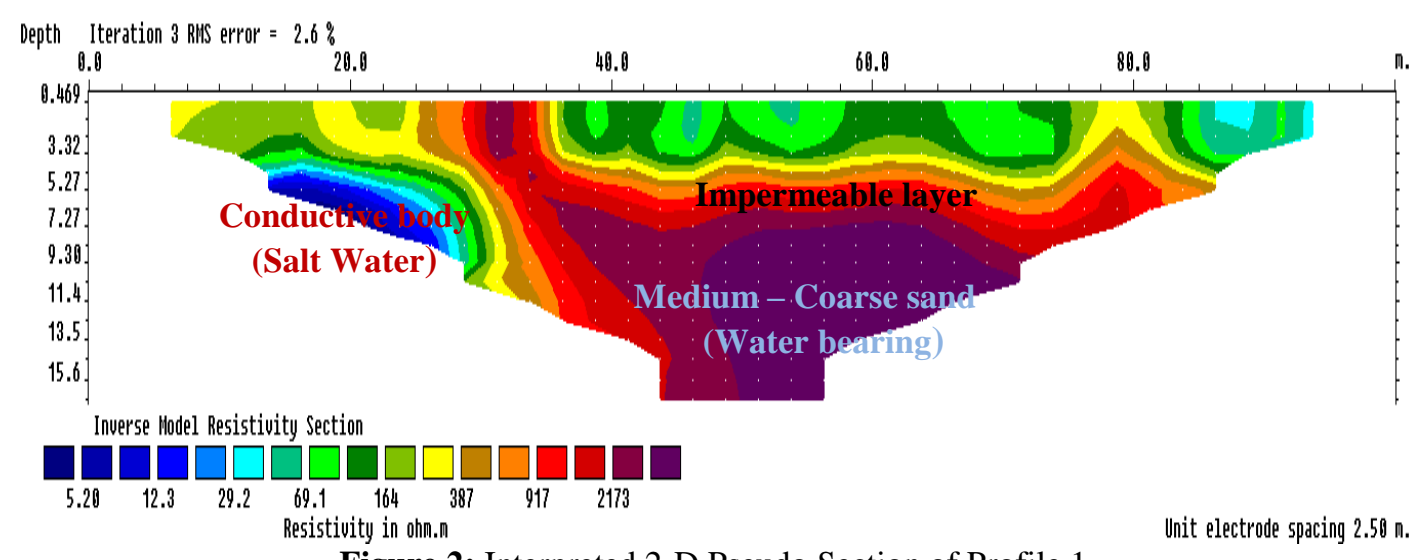

Figure 2: Interpreted 2-D Pseudo Section of Profile 1. 

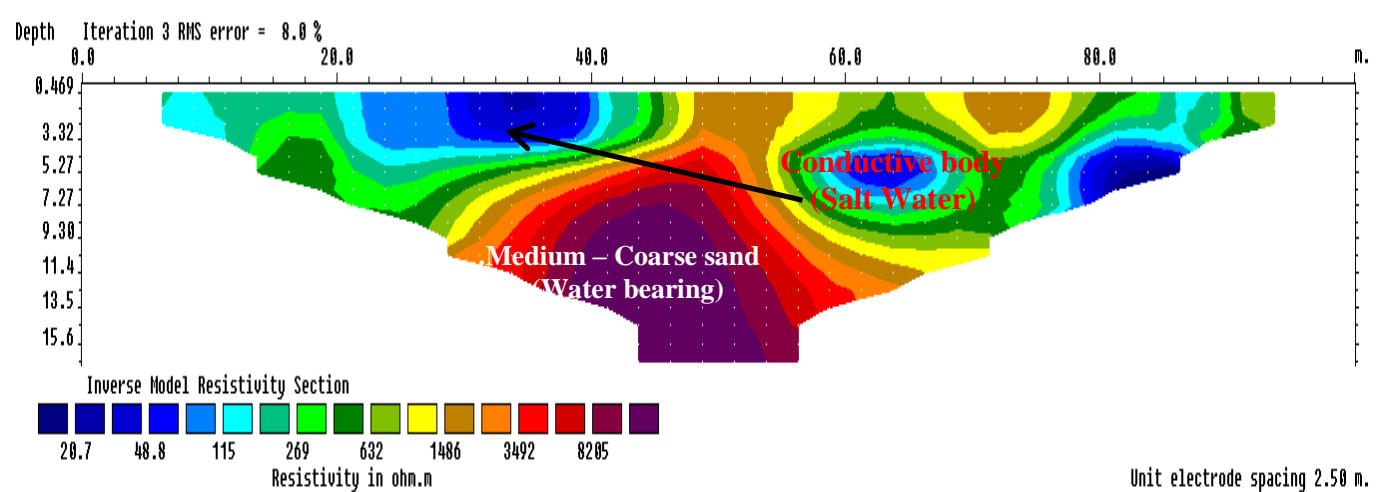

Figure 3: Processed 2-D Pseudo Section of Profile 2.

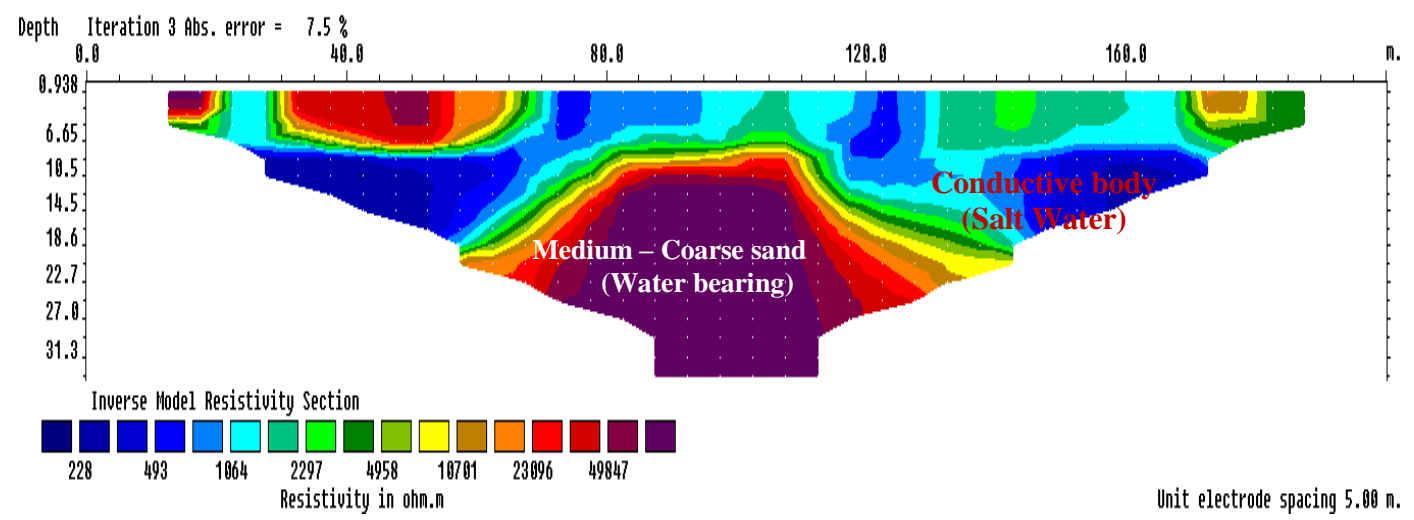

Figure 4: Processed 2-D Pseudo Section of Profile 3.

Table 1: Summarized results of data interpretation for VES 1.

\begin{tabular}{|c|c|c|c|c|}
\hline VES Location & Geoelectric Layer & Resistivity ( $\square$-m) & Depth (m) & Thickness (m) \\
\hline & 1 & 76.70 & 1.94 & 1.94 \\
\hline & 2 & 366.00 & 4.52 & 2.58 \\
\hline 1 & 3 & 1527.00 & 18.40 & 13.88 \\
\hline & 4 & 2459.00 & 41.70 & 23.30 \\
\hline & 5 & 747.00 & - & - \\
\hline
\end{tabular}

Table 2: Summarized results of data interpretation for VES 2.

\begin{tabular}{|c|c|c|c|c|}
\hline VES Location & Geoelectric Layer & Resistivity ( $\square-\mathbf{m})$ & Depth (m) & Thickness (m) \\
\hline \multirow{4}{*}{2} & 1 & 336.00 & 1.89 & 1.89 \\
\cline { 2 - 5 } & 2 & 691.00 & 4.86 & 2.97 \\
\cline { 2 - 5 } & 3 & 1636.00 & 18.72 & 13.86 \\
\cline { 2 - 5 } & 4 & 3608.00 & 42.90 & 24.18 \\
\cline { 2 - 5 } & 5 & 1665.00 & - & - \\
\hline
\end{tabular}

From the curves the presence of five (5) geoelectric sections has already been established and this is also represented in tables 3.3 and 3.4. In the two VES Locations, the first geoelectric layer has a resistivity value ranging from $76.70 \Omega-\mathrm{m}$ to $336.00 \Omega-\mathrm{m}$. The depth range is from the surface to $1.94 \mathrm{~m}$ in both sections with a thickness varying from $1.89 \mathrm{~m}$ to $1.94 \mathrm{~m}$. This first geoelectric layer consists of the Top soil. The second geoelectric layer has resistivity ranging from $366.00 \Omega-\mathrm{m}$ to $691.00 \Omega-\mathrm{m}$ and a depth variation from $4.86 \mathrm{~m}$ to $4.52 \mathrm{~m}$. It has a thickness range from $2.58 \mathrm{~m}$ to $2.97 \mathrm{~m}$ and it is made up of mainly laterite. The third geoelectric layer is assumed to be an impermeable layer and could be referred to as a confining layer to the aquifer. It has a resistivity range of $1527.00 \Omega-\mathrm{m}$ and $1636.00 \Omega-\mathrm{m}$, occurring at a depth between $18.40 \mathrm{~m}$ and $18.72 \mathrm{~m}$ with a varying thickness between $13.86 \mathrm{~m}$ and $13.88 \mathrm{~m}$. It is made up of Clayey mineral and some percentage of sand (Clayey-sand). The geoelectric interpretation also shows that the fourth layer has a resistivity value which lies

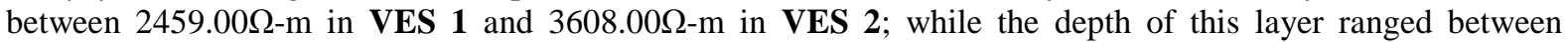
$41.70 \mathrm{~m}$ and $42.90 \mathrm{~m}$. It has a varying thickness range of $23.30 \mathrm{~m}$ in VES 1and $24.18 \mathrm{~m}$ in VES 2. It is comprised of medium to coarse grain sand. This layer constitutes the aquifer layer hence groundwater can be sourced from this layer. The resistivity of the fifth layer which comprises of Clayey mineral, probably shale, lies between

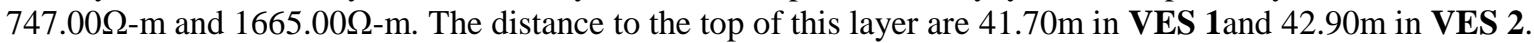




\section{Discussion Of Results}

The Benin Formation which the study area is part of is known to consist of sands, sandstones, and gravels, with intercalations of clay and sandy clay. The sands are fine-medium-coarse grained and poorly sorted [9]; [10]. This is evident in the results of the Vertical Electrical Sounding data obtained from the two VES locations.

The five(5) geoelectric layers interpreted as top soil, laterite, clayey-sand, waterized sand (finemedium-coarse grained sand) are observed to be continuous within the two locations with correlating depths and thickness of the various sections. This presumably has resulted to the existence of the same curve types.

The resistivity of the first geoelectric layer occurring at a depth of $1.94 \mathrm{~m}$ from the surface having a thickness of $1.89 \mathrm{~m}$ to $1.96 \mathrm{~m}$ ranged from $76.70 \Omega-\mathrm{m}$ to $336.00 \Omega-\mathrm{m}$; while the second layer with a thickness of $2.58 \mathrm{~m}$ to $2.97 \mathrm{~m}$ has resistivity values ranging from $366.00 \Omega-\mathrm{m}$ to $691.00 \Omega-\mathrm{m}$. It is evident that the aquiferous layer occupying the fourth layer position with a varying thickness of $23.30 \mathrm{~m}$ in VES 1 and $24.180 \mathrm{~m}$ in VES 2 has an impermeable layer directly above it (made up of clay minerals (silty in nature) and sand bodies); and preventing it from unwanted seepages from the surface and overlying layers. The resistivity of the aquifer lies

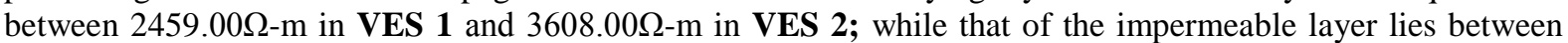
$1527.00 \Omega-\mathrm{m}$ and $1636.00 \Omega-\mathrm{m}$ with thickness of the range $13.86 \mathrm{~m}$ and $13.88 \mathrm{~m}$. The thickness of the aquifer is adequate to retain reasonable quantity of potable groundwater.

The $2 \mathrm{D}$ resistivity and VES data when combined gives a more reliable structure of the subsurface and the groundwater quality of any locality. The low resistivity zone as mapped out in the 2D relates with the first two layers as interpreted in the two VES locations. The third layers interpreted as clay as obtained in the two VES data corresponds to the impermeable layer identified in the two $2 \mathrm{D}$ profiles. This impermeable layer separates the saline water from infiltrating into the fresh water zone. From the above analysis potable groundwater can be obtained between the depths of $20.00 \mathrm{~m}$ to $43.00 \mathrm{~m}$ within this vicinity.

\section{Conclusion}

An integrated approach to groundwater exploration offers a reliable assessment of the potentials and quality of the groundwater resources in an area. The results show that an aquifer system that is free from any form of contamination can be obtained at a reasonable depth of $19.00 \mathrm{~m}$ and above. The area has good prospects as far as groundwater resources are concerned. Vertical Electrical Sounding (VES) has proved to be very reliable for ground water studies and therefore the method can excellently be used for shallow and deep ground water geophysical resistivity investigation. The study area reveals moderate to high groundwater potential based on the aquifer characteristics. It will be necessary to recommend that subsequent borehole drilling for groundwater within the study area should be drilled to a total depth between $43.0 \mathrm{~m}$ and $45.0 \mathrm{~m}$; and cased between 20.0 to $42.0 \mathrm{~m}$. It will be suggested that a more elaborate and detailed study be conducted within this area to fully reveal the extent of the salt water exposed by the 2-D towards the North-West direction.

\section{Acknowledgements}

We wish to acknowledge the effort and support of the community heads in Ogu/Bolo Local Government Area of Rivers State while carrying out this study.

\section{References}

[1]. Olorunfemi, M.O., Ojo, J.S. and Akintunde, O.M. 1999. "Hydrogeophysical Evaluation of the Groundwater Potential of Akure Metropolis, South-Western Nigeria”. Journal of Mining and Geology. 35(2):207 - 228.

[2]. Odukoya, O.A., Arowolo, T.A., Bamgbose, O. (2002). Effect of solid waste. Landfill on underground and surface water quality at Ring Road, Ibadan. Global J. Environ. Sci., 2(2): 235-242. Ogwueleka TC (2003). Analysis of Urban Solid Waste in Nsukka, Nigeria. J. Solid Waste Technol. Mgt. 29:239-246.

[3]. Agbalagba O. E.1., Agbalagba O. H., Ononugbo C. P. and Alao A. A (2011). Investigation into the physicochemical properties and hydrochemical processes of groundwater from commercial boreholes In Yenagoa, Bayelsa State, Nigeria. A. J. Environ. Sci. Technol. Vol. 5(7), pp. 473-481

[4]. Ehirim, C.N. and W. Ofor, 2011. Assessing aquifer vulnerability to contaminants near solid waste landfill sites in a coastal environment, Port Harcourt, Nigeria. Trends Applied Sci. Res., 6: 165-173.

[5]. Ehirim, C.N. and Ebeniro, J.O. 2006. "Tectonic Trends Delineated from Drainage Lineament Analysis and Azimuthal Resistivity Survey: A Case Study of S. E. Nigeria Gully Erosion Belt". Global Journal of Pure and Applied Sciences. 4(1):21-28.

[6]. Loke, M.H. 1999, Electrical Imaging Surveys for Environmental and Engineering Studies. A Practical Guide to 2D and 3D Surveys. Advanced Geosciences, Inc.: Austin, TX. 57.

[7]. Keller, G.V. and Frischknecht, F.C. 1988. Electrical Methods in Geophysical Prospecting. Pergamon Press Inc.: New York, NY. $38-39,519$

[8]. Henker, C.J. 1985. Schlumberger Automatic Analysis Software. University of Amsterdam, Version 0.92.

[9]. Whiteman, A. J. (1982). Nigeria: Its petroleum geology, resources and potentials. (1) 176, (2) 238. Graham and Trotman, London, U.K.

[10]. Uma, K. O., Egboka, B. C. E.. Water resource of Owerri and its environs, Imo State, Nigeria. Journal of Mining and Geology, 1985, 22(1\&2): $57-64$ 